University of Windsor

Scholarship at UWindsor

2016

\title{
DETERMINATION OF PCB ELIMINATION COEFFICIENTS IN ROUND GOBY AND TUBENOSE GOBY
}

Xin Sun

University of Windsor

Tim B. Johnson

Ontario Ministry of Natural Resources and Forestry

Ken G. Drouillard

Follow this and additional works at: https://scholar.uwindsor.ca/glierpub

Part of the Biochemistry, Biophysics, and Structural Biology Commons, and the Physical Sciences and Mathematics Commons

\section{Recommended Citation}

Sun, Xin; Johnson, Tim B.; and Drouillard, Ken G.. (2016). DETERMINATION OF PCB ELIMINATION COEFFICIENTS IN ROUND GOBY AND TUBENOSE GOBY. Bulletin of Environmental Contamination and Toxicology.

https://scholar.uwindsor.ca/glierpub/123

This Article is brought to you for free and open access by the Great Lakes Institute for Environmental Research at Scholarship at UWindsor. It has been accepted for inclusion in Great Lakes Institute for Environmental Research Publications by an authorized administrator of Scholarship at UWindsor. For more information, please contact scholarship@uwindsor.ca. 
DETERMINATION OF PCB ELIMINATION COEFFICIENTS IN ROUND

2 GOBY AND TUBENOSE GOBY

3 Xin Sun ${ }^{1}$, Tim B Johnson ${ }^{2}$, Ken G. Drouillard ${ }^{1}$

$4{ }^{1}$ Great Lakes Institute for Environmental Research, University of Windsor, Windsor, 5 ON N9B 3P4, Canada. ${ }^{2}$ Glenora Fisheries Station, Ontario Ministry of Natural

6 Resources and Forestry, Picton, ON K0K 2T0, Canada.

\begin{abstract}
Whole-body elimination coefficients of polychlorinated biphenyls (PCBs) were determined in two Great Lakes invasive fish species, round goby (Neogobius melanostomus) and tubenose goby (Proterorhinus semilunaris). Elimination rates were determined for a set of model PCB congeners ( $\mathrm{n}=12$ congeners) dosed to fish by intraperitoneal injection and allowed to depurate at a temperature of $21.4^{\circ} \mathrm{C}$ for $90 \mathrm{~d}$. Eight PCBs (PCB 6, 13, 21, 57, 62, 68, 89, 112 and 125) exhibited significant elimination by round goby and had corresponding half lives ranging from 13 to $39.8 \mathrm{~d}$. For tubenose goby, four congeners (PCBs 21, 58, 62 and 68) exhibited significant elimination with half lives in the range from 18.8 to $48.8 \mathrm{~d}$. Whole-body elimination rate coefficients were significantly higher for round gobies compared to tubenose goby. In both cases, PCB elimination rate coefficients were negatively related to chemical $\log$ Kow.
\end{abstract}

Key words: polychlorinated biphenyls, toxicokinetics, round goby, tubenose goby.

\title{
Introduction
}

Persistent organic pollutants (POPs), as exemplified by polychlorinated biphenyls (PCBs) have high bioaccumulation potentials in organisms and food webs (Connolly and Pedersen 1988; Gobas et al. 1993). Even though PCB production has been banned in North America since the 1970's, these contaminants remain the largest contributor to sportfish consumption advisories in the Laurentian Great Lakes (Scheider et al. 1998). Part of the remarkable persistence of these chemicals is due to their slow environmental degradation rates and strong association with sediment organic matter which has resulted in the accumulation of large reservoirs of contaminated sediments in several Great Lakes Areas of Concern. PCBs also tend to concentrate in surficial sediments, achieving not only high concentrations, but also higher chemical potentials (or chemical fugacity) compared to overlying waters (Gobas and Maclean 2003). This leads to an enhancement of the benthic exposure pathway for chemical entry into food webs (Morrison et al. 2000).

The Great Lakes have also been subject to invasive species stressors which further reinforce the benthic food web. The establishment of dreissenid mussels in the mid-1980's contributes to nutrient entrainment in sediments and increases in benthic productivity at the expense of offshore algal production (Hecky et al. 2004). Following dressinid invasion, round gobies capable of feeding on dreissenids and tubenose goby entered the system and provided new benthic/pelagic food web linkages capable of shunting sediment associated contaminants to sport fish (Johnson 
et al. 2005). Noteworthy, smallmouth bass (Micropterus dolomieu), walleye (Sander vitreus) and lake trout (Salvelinus namaycush), all highly sought after sport fish, readily incorporate invasive gobies in their diets (Thomas et al. 2002).

Although bioaccumulation kinetics of PCBs in fish have been documented in many fish species (Niimi and Oliver 1983; Fisk et al. 1998; Paterson et al. 2007) and a bioaccumulation model has been described for round goby ( $\mathrm{Ng}$ and Gray 2011), there are no empirical studies measuring PCB toxicokinetics in gobies. The objective of this study was to measure whole-body elimination coefficients $\left(k_{\mathrm{tot}}\right)$ for a set of PCB congeners in round goby and tubenose goby and to compare empirically derived chemical toxicokinetics between the two fish species.

\section{Methods}

Twenty four fish of each species were collected from the Detroit River by seine

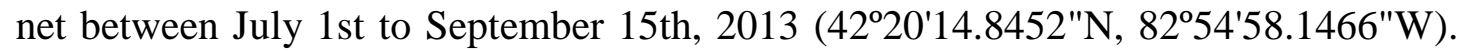
At the time of collection, the more abundant round gobies were size-graded to as closely match sizes of tubenose gobies being captured. Fish were transported to the laboratory at the University of Windsor within $3 \mathrm{~h}$ of their field collection.

Individuals of each species were held in a $550 \mathrm{~L}$ polyethylene tank divided into four sections using plastic mesh inserts. Two larger partitions held 20 round and 20 tubenose gobies and two smaller partitions held 4 round and 4 tubenose gobies as controls. The tank was set up as a recirculating system in which water was pumped in and drained to a larger reservoir under constant aeration and temperature control. A biofiltration unit containing activated charcoal was added to the reservoir to maintain water quality. The photoperiod was kept at ambient environmental conditions. Fish were fed live California black-worms (Lumbriculus variegatus; Aquatic Foods Company, California, USA) to satiation every other day throughout the acclimation and experimental duration. Water temperatures were measured daily by digital temperature loggers submersed in the tank. Water quality was monitored weekly by measuring $\mathrm{pH}$, dissolved oxygen, temperature and specific conductance.

Fourteen environmentally uncommon PCBs were used to dose fish so as not to co-elute with PCBs bioaccumulated by fish from the field. The selection of the congeners was based on Frame et al. (1996) who reported on the distribution of individual PCBs in 17 commercial Aroclor Mixtures. All selected congeners were either non-detected or $<0.03 \%$ of total PCBs present in commercial Aroclor mixtures. The exceptions were PCB 6 which had up to 3.84\% composition in lesser used light Aroclor mixtures (Aroclor 1221, 1232) but exhibits lower environmental persistence and PCB 13 (up to $1.12 \%$ in Aroclor 12.21 and $<0.7 \%$ in other mixtures). The second criteria was based on relative retention indices (Chu and Hong, 2004) of the selected PCBs which were chosen to be sufficiently different on a DB-5 column from environmentally common Aroclor PCBs enabling their separation by GC-ECD. The third criteria for selection of model PCBs was based on the distribution of hydrophobicity (log Kow from 5.02 to 7.55; Hansen et al., 1999) which encompassed the range of hydrophobicity or environmentally common PCBs. The selected dosing mixture contained PCBs (IUPAC \#s): 6, 13, 21, 23, 43, 62, 89, 57, 68, 112, 125, 166, 
204 and 205 derived from individual standards of neat chemical (AccuStandard, New Haven, CT, USA). The above PCB congeners, henceforth referred to as 'model PCBs', and were selected based on the above criteria and were considered unlikely to have bioaccumulated in fish collected from the Detroit River and used as study specimens. Prior to dosing, experimental fish were weighed, sexed and measured for total length after light anesthesia using MS-222. Each fish was administered an intraperitoneal injection (IP) as described in O'Neil et al. (2013). The volume of injection was $0.5 \mathrm{uL}$ dosing oil/g body weight to achieve nominal target doses of $20 \mathrm{ng} / \mathrm{g}$ for PCBs 6,13 , $23,43,62,89,68,112,125,166,204,205 ; 25 \mathrm{ng} / \mathrm{g}$ for PCB 21; and 100ng/g for PCB 57. Control fish were sham dosed with an equivalent volume of sunflower oil. Following injection, fish were allowed to recover and placed back into the experimental tank. Fish were held $2 \mathrm{~d}$ before sampling to allow tissue re-distribution of the injected PCBs (O’Neil et al. 2013). Four fish of each species were destructively sampled on day 0 (2 days following IP injection), 15, 30, 60 and 90. At each sacrifice, fish were weighed, measured for total length and sexed. Control fish were sampled on Day 0 and Day 90. This study was conducted under ethical approval from the University of Windsor's Animal Care Committee.

The neutral lipid and PCB content of whole-body homogenates of each fish was analyzed by solid/liquid chromatography as described in Daley et al. (2009). Prior to extraction, each sample was spiked with $200 \mathrm{ng}$ of PCB 34 as a recovery standard. Neutral lipids was determined gravimetrically by removing $10 \%$ of the dichloromethane/hexane $(1: 1 \mathrm{v} / \mathrm{v})$ used for PCB extractions. The remaining extract was cleaned up by florisil chromatography described in Lazar et al. (1992). Modifications to the clean-up procedure involved use of $50 \mathrm{~mL}$ of hexane to collect the first fraction followed by a second fraction consisting of $50 \mathrm{~mL} 15: 85(\mathrm{v} / \mathrm{v})$ dichloromethane:hexane. Each fraction was collected in separate receiving flasks and concentrated to a final volume of $1 \mathrm{~mL}$ in isooctane. Analytical determination of PCBs was performed by gas chromatography-electron capture detection (GC-ECD) (Lazar et al. 1992). For each set of 4 samples extracted, a, method blank, internal reference tissue homogenate (Detroit River Carp), PCB 34 recovery standard, external PCB standard (Quebec Ministry of Environment Congener mix; AccuStandard, New Haven, CT, USA) and non-environmental PCB standard (AccuStandard, New Haven, CT, USA) was analyzed. Analytical precision was checked by comparing native PCBs in reference homogenates with laboratory control charts and found to be within 2 standard deviations of the control chart values for each batch. Mean internal standard recoveries for PCB 34 were $64.5 \pm 18.9 \%$. Owing to the low recoveries in a few samples, all data were PCB 34 recovery corrected. Data for two tubenose gobies (1 day 0 and day 90 replicate) were eliminated due to recoveries $<30 \%$ and or very large PCB205 correction factors (see below). Detection limits ranged from 0.01 to 0.05 ng/g wet weight.

After testing normality via probability plots, variables related to fish body weight and fish lipid mass were ln-transformed to conform to normality. Analysis of variance (ANOVA) was used to test for differences in body weight or lipid mass between the species and through time and also to test for the species $\mathrm{x}$ time interaction (i.e. 
growth). The $k_{\text {tot }}$ values were determined by linear regression of $\ln$ lipid equivalent PCB concentration ( $\mathrm{ng} / \mathrm{g}$ lipid equivalent) versus time and establishing $k_{\text {tot }}$ as the slope from the above relationship following control correction of the data by subtraction of the mean PCB concentration in controls from each treatment fish. Non-detected values were removed from linear regressions.

Close attention was paid to PCB 205 as the most hydrophobic PCB present in the dosing solution $(\log$ Kow $=7.55)$ and expected to be eliminated at the slowest rate. For this congener, both a mass balance (trend in total mass of PCB 205 in fish with time) and lipid normalized concentrations with time indicated non-significant loss of chemical from fish over $90 \mathrm{~d}$. For example, round and tubenose gobies showed a weak but non-significant positive slope of PCB 205 mass in fish with time ( $p>0.1$ and p $>0.5$ for round and tubenose goby, respectively; ANOVA). Given that PCB 205 showed no evidence of elimination, it was subsequently used as a conservative tracer to correct lipid concentrations of other PCB congeners present in the dosing mixture. This correction accounts for individual differences in the assimilated dose of PCBs from the IP injection as well as growth dilution and/or weight loss that may have occurred over the study. The PCB-205 correction was as follows:

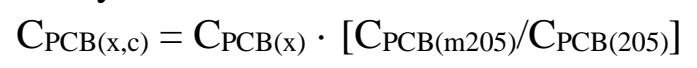

Where $\mathrm{C}_{\mathrm{PCB}(\mathrm{x})}$ is the lipid equivalent concentration ( $\mathrm{ng} / \mathrm{g}$ lipid equivalent) of congener (x) in the sample, $\mathrm{C}_{\mathrm{PCB}(\mathrm{m} 205)}$ is the mean lipid equivalent concentration (ng/g lipid equivalent) of PCB 205 measured in all fish from the same species over the study and $\mathrm{C}_{\mathrm{PCB}(205)}$ is the lipid equivalent concentration (ng/g lipid equivalent) of PCB 205 measured in the sample fish. Thus, for all congeners except PCB 205, $k_{t o t}$ was determined as the slope of a linear regression of $\ln \mathrm{C}_{\mathrm{PCB}(\mathrm{x}, \mathrm{c})}$ versus time. Control correction was performed prior to PCB 205 correction. $k_{t o t}$ values were only reported for congeners which demonstrated a significant slope. To test for differences in $k_{\text {tot }}$ between species, the data on $\ln$ transformed control corrected $\mathrm{C}_{\mathrm{PCB}(\mathrm{x}, \mathrm{c})}$ with time was reduced using principle components analysis (PCA). PCA requires a full data matrix. Thus non-detected values were replaced with the detection limit for a given time point. ANCOVA was performed on PCA-scores for significant PCA axes to test for species $\mathrm{x}$ time interactions. Lillefor's test for normality of PCA-1 scores and Levene's test of homogeneity of variance were used to test ANOVA assumptions and found to be valid, i.e. $\mathrm{p}$-values $>0.05$.

\section{Results and Discussion}

Water temperatures were constant at $21.40 \pm 0.48{ }^{\circ} \mathrm{C}$ and exhibited no change with time. No fish mortalities occurred throughout the study. The mean whole-body weights \pm standard error (SE) for round and tubenose gobies were $2.88 \pm 0.06 \mathrm{~g}$ and $2.85 \pm 0.05 \mathrm{~g}$ and were not significantly different from one another $(\mathrm{p}>0.5)$. The mean \pm SE whole-body lipid contents of round and tubenose gobies were $4.07 \pm 0.35 \%$ and $3.93 \pm 0.31 \%$, respectively and were not significantly different from each other $(p>0.05)$. Neither lipid nor body weight showed significant changes $(p>0.05)$ with time.

Dosed PCBs were not detected in analytical blanks run with sample batches. 
PCBs 23 and 43 suffered from analytical interferences in the samples which prevented accurate quantitation. In the case of PCB 23, the co-eluting chemical was identified as native PCB 49. The interference with PCB 43 was not identified. These compounds were therefore removed from the data set. Control fish had non-detectable concentrations for PCB 6 and 13. However the remaining PCBs were observed at concentrations in control fish and ranged from 0.6 to $20.3 \%$ of concentrations measured in Day 0 treatment fish (Table 1). There was no evidence for an increase in control PCB residues with time. This implies that fish were in steady state with their food over the course of the acclimation and study period. Therefore, the mean control concentration for day 0 and 90 fish for each species was subtracted from each treatment fish prior to analyzing the data.

Significant elimination of PCBs 6, 21, 57, 62, 68, 89, 112 and 125 was observed for round goby (Table 2). For tubenose goby, significant elimination was observed for PCBs 21, 57, 62 and 68 (Table 2). PCB 13 in both species and PCB 6 in tubenose goby exhibited large numbers of non-detection values that prevented credible $k_{\text {tot }}$ values from being determined. Figure 1 presents elimination trends for 3 selected PCBs (PCBs 21, 57 and 68) that underwent elimination from both species. PCB concentrations were generally similar between Day 0 and 15 for most of the dosed chemicals and for some congeners (e.g. PCB 57) more variable for the day 30 time point. Slower elimination between the first time points may have occurred as a result of lags in inter-tissue distribution of PCBs to slowly perfused storage compartments such as fat and skin.

A PCA was performed on the data matrix comprising of control and PCB 205 corrected concentrations of PCBs 6, 13, 21, 57, 62, 68, 89, 112, 125, 166 and 204. The first, second and third principle components had eigenvalue greater than 1 and each component explained 50.1, 18.0 and $9.6 \%$ of the variation of the data. Loadings of individual PCBs to each PCA axis is summarized in Table 3. PCA 1 had strong positive loadings (correlation coefficients $>0.70$ ) for PCBs 21, 57, 62, 68, 89 and 125 (Table 2) all of which showed significant elimination by one or two species. The $2^{\text {nd }}$ and $3^{\text {rd }}$ PCA axes were associated with PCBs that did not undergo significant elimination (e.g. PCB 166 for PCA 2 and PCB 204 for PCA 3) and were not considered further. The ANCOVA for PCA scores on the first component axis showed time as a significant variable ( $\mathrm{p}<0.001$; ANCOVA) as well as a significant species $\mathrm{x}$ time ( $\mathrm{p}<0.01$; ANCOVA) interaction term. This indicates that round gobies more rapidly eliminated PCBs compared to tubenose goby.

Table 1. Concentrations (ng/g lipid equivalent) of dosed PCBs in control and day 0 treatment fish

\begin{tabular}{l|lll|lll}
\hline \multirow{3}{*}{ Chemical } & \multicolumn{2}{|l|}{ Round Goby } & \multicolumn{4}{l}{ Tubenose Goby } \\
& Control & Treatment & $\%$ in & Control & Treatment & $\%$ in \\
& Mean \pm SE & Mean \pm SE & Control & Mean \pm SE & Mean \pm SE & Control \\
\hline PCB 6 & $<0.05$ & $223.3 \pm 57.1$ & 0 & $<0.05$ & $44.7 \pm 11.7$ & 0 \\
PCB 13 & $<0.05$ & $127.8 \pm 56.9$ & 0 & $<0.05$ & $85.5 \pm 57.8$ & 0
\end{tabular}




\begin{tabular}{l|lll|lll} 
PCB 21 & $8.6 \pm 1.3$ & $257.9 \pm 102.9$ & 3.3 & $3.3 \pm 2.9$ & $206.0 \pm 140.2$ & 1.4 \\
PCB 62 & $1.4 \pm 1.4$ & $220.3 \pm 87.3$ & 0.6 & $0.6 \pm 5.3$ & $222.1 \pm 120.3$ & 2.4 \\
PCB 68 & $6.9 \pm 4.0$ & $221.6 \pm 86.1$ & 3.1 & $3.1 \pm 5.5$ & $233.9 \pm 115.8$ & 2.4 \\
PCB 57 & $14.0 \pm 14.1$ & $1108 \pm 445$ & 1.3 & $1.3 \pm 15.6$ & $1133 \pm 589$ & 1.4 \\
PCB 89 & $26.6 \pm 14.4$ & $224.7 \pm 89.4$ & 11.8 & $23.7 \pm 9.4$ & $239.5 \pm 125.6$ & 9.9 \\
PCB 112 & $50.3 \pm 29.0$ & $248.0 \pm 98.8$ & 20.3 & $58.0 \pm 24.8$ & $306.0 \pm 133.9$ & 18.9 \\
PCB 125 & $9.4 \pm 7.2$ & $207.2 \pm 79.1$ & 4.5 & $4.5 \pm 1.7$ & $290.4 \pm 165.8$ & 1.5 \\
PCB 166 & $26.9 \pm 14.0$ & $229.5 \pm 87.5$ & 11.7 & $25.4 \pm 17.3$ & $225.9 \pm 121.2$ & 11.3 \\
PCB 204 & $11.8 \pm 10.0$ & $237.4 \pm 89.5$ & 5.0 & $5.0 \pm 7.0$ & $263.7 \pm 143.4$ & 2.7 \\
PCB 205 & $7.2 \pm 5.8$ & $232.4 \pm 84.7$ & 3.1 & $3.1 \pm 8.3$ & $511.5 \pm 335.4$ & 1.6 \\
\hline
\end{tabular}

214

215

216

217

218

219

220

221

222

223

224

225

226

227

228

229 230

PCB elimination rate coefficients and half lives for gobies were similar to those observed for other small fish held near to their preferred water temperature. Paterson et al. (2007) reported elimination of PCBs in yellow perch (Perca flavescens; $4.7 \mathrm{~g}$ fish) during a warm temperature period $\left(22^{\circ} \mathrm{C}\right)$. Half lives of PCBs for yellow perch over a similar Kow range as reported in the present study were from 26 to 72 days. $\mathrm{Li}$ et al. (2015) reported elimination of PCBs in $2.3 \mathrm{~g}$ goldfish (Carassius auratus) held at $21^{\circ} \mathrm{C}$. Half lives of PCBs from Li et al.'s study ranged from 33 to 58 days over the equivalent Kow range. Hattula and Karlog (1973) reported a half-life for sum PCBs of 21 days in goldfish $(1.8 \mathrm{~g})$ held at 21 to $23^{\circ} \mathrm{C}$, which corresponds to an elimination rate of $0.03 \mathrm{day}^{-1}$. Fisk et al. (1998) reported half lives of PCBs in $10 \mathrm{~g}$ rainbow trout (Oncorhynchus mykiss) occupying $12^{\circ} \mathrm{C}$ waters, which is close to their preferred temperature, that ranged from 29 to $79 \mathrm{~d}$ for equivalent Kow congeners.

Table 2. Whole-body elimination coefficients $\left(k_{\mathrm{tot}}\right)$ and half lives $\left(\mathrm{t}_{1 / 2}\right)$ for significantly $(\mathrm{p}<0.05)$ eliminated PCBs in round and tubenose goby.

\begin{tabular}{cc|ccc|ccc}
\hline & & \multicolumn{3}{|c|}{ Round Goby } & \multicolumn{3}{c}{ Tubenose Goby } \\
Chemical & Log & $k_{\mathrm{tot} \pm \mathrm{SE}}$ & $\mathrm{t}_{1 / 2}$ & $\mathrm{n}, \mathrm{R}^{2}$ & $k_{\mathrm{tot}} \pm \mathrm{SE}$ & $\mathrm{t}_{1 / 2}$ & $\mathrm{n}, \mathrm{R}^{2}$ \\
& Kow & $\left(\mathrm{d}^{-1}\right)$ & $(\mathrm{d})$ & & $\left(\mathrm{d}^{-1}\right)$ & $(\mathrm{d})$ & \\
\hline PCB 6 & 5.02 & $0.054 \pm 0.018$ & 13.0 & $12,0.43$ & $\mathrm{NS}$ & & \\
PCB 21 & 5.41 & $0.040 \pm 0.006$ & 17.2 & $13,0.78$ & $0.037 \pm 0.010$ & 18.8 & $16,0.44$ \\
PCB 57 & 5.97 & $0.037 \pm 0.005$ & 18.8 & $19,0.71$ & $0.018 \pm 0.005$ & 38.5 & $18,0.43$ \\
PCB 62 & 5.73 & $0.045 \pm 0.007$ & 15.3 & $19,0.70$ & $0.014 \pm 0.004$ & 48.8 & $18,0.35$ \\
PCB 68 & 6.06 & $0.032 \pm 0.007$ & 21.7 & $20,0.48$ & $0.015 \pm 0.005$ & 45.1 & $18,0.37$ \\
PCB 89 & 6.06 & $0.034 \pm 0.009$ & 20.3 & $15,0.46$ & NS & & \\
PCB 112 & 6.22 & $0.017 \pm 0.005$ & 39.8 & $17,0.39$ & NS & & \\
PCB 125 & 6.27 & $0.018 \pm 0.004$ & 37.8 & $20,0.56$ & NS & & \\
\hline
\end{tabular}

$\mathrm{NS}=$ Non-significant elimination.

Other studies have observed negative relationships between PCB hydrophobicity and their respective elimination rate coefficients from fish (Niimi and Oliver, 1983; Paterson et al. 2007; Li et al., 2015). In the present study, both round and tubenose goby $\mathrm{k}_{\text {tot }}$ values significantly $(\mathrm{p}<0.05$; each species) decreased as a function of 
chemical Kow according to the following relationships:

Round goby: $\quad \log \mathrm{k}_{\mathrm{tot}}=-0.32 \pm 0.11 \cdot \log \mathrm{K}_{\mathrm{ow}}+0.40 \pm 0.64 ; \mathrm{r}^{2}=0.51 ; \mathrm{p}<0.05$ (Eq. 2 ) Tubenose goby: $\log \mathrm{k}_{\text {tot }}=-0.64 \pm 0.13 \cdot \log \mathrm{K}_{\mathrm{ow}}+1.97 \pm 0.76 ; \mathrm{r}^{2}=0.89 ; \mathrm{p}<0.05$ (Eq. 3 )

Figure 2 provides a plot of $\log \mathrm{k}_{\text {tot }}$ as a function of chemical $\mathrm{K}_{\mathrm{Ow}}$ in each species along with 95\% confidence intervals around each regression fit. Although PCB 21 had a similar elimination rate in the two species (Figure 1 and 2), PCBs 57, 62 and 68 had from 2.0 to 3.2 fold higher elimination rates from round goby consistent with the PCA ANCOVA results.

However, some caution in the over interpretation of differences in slopes from Eqs. 2 and 3 are warranted. Only a small number of PCB congeners $(n=4)$ exhibited significant elimination from tubenose gobies and having a larger number of compounds over a larger range of chemical hydrophobicity would be desirable. The

Table 3. Principle components analysis of PCBs in round and tubenose goby.

\begin{tabular}{|l|l|l|l|}
\hline $\begin{array}{l}\text { Principle } \\
\text { Component }\end{array}$ & Eigenvalue & $\begin{array}{l}\text { \% Variance } \\
\text { Explained }\end{array}$ & $\begin{array}{l}\text { PCB congeners with strong } \\
\text { loadings onto a given } \\
\text { component }^{1}\end{array}$ \\
\hline PCA 1 & 5.52 & 50.14 & PCBs 21, 57, 62, 68, 89, 125 \\
\hline PCA 2 & 1.98 & 17.96 & PCBs 112, 166 \\
\hline PCA 3 & 1.06 & 9.65 & PCB 204 \\
\hline
\end{tabular}

${ }^{1}$ PCB congeners having correlation coefficients exceeding 0.7 onto a given Principle component were considered strongly associated with the component.

small number of PCB congeners used in the present research was due to experimental constraints that resulted from the choice of test species used. Experimental fish had to be collected from contaminated field locations as they are not available as laboratory cultures. While round goby is widely distributed throughout the Laurentian Great Lakes, tubenose goby has remained restricted in its distribution largely to the Huron-Erie corridor and western Lake Erie necessitating their collection from contaminated field locations (Vanderploeg et al., 2002; Kocovsky et al., 2011). These constraints necessitated dosing fish with model PCBs as opposed to more common PCB congeners found in the natural environment. Even so, control animals were observed to contain small amounts of the dosed PCBs that may have been accumulated in the field or present in trace amounts in the food fed to fish that necessitated control correction. Ideally, use of ${ }^{13} \mathrm{C}$-labelled PCBs in the dosing mixture would circumvent this issue, although at a greatly increased expense in the procurement of dosing compounds. The PCBs dosed to fish in the present study were selected as model compounds that exhibit a range of hydrophobicity's comparable to the range of hydrophobicity found in environmentally common PCBs. It is thus argued that the relationships generated by this research are still relevant to environmentally common PCBs. This is because PCB toxicokinetics in fish is 
dominated by diffusive flux across fugacity gradients between the fish and water/feces which is ultimately regulated by physical properties of congeners such as lipid/water solubility and Kow. Indeed, Drouillard et al., (2007) demonstrated that a similar set of model PCBs (PCB 7, 23, 61, 109 and 173) exhibited similar elimination rate coefficients from the freshwater mussel (Elliptio complanata) as Aroclor PCBs.

Overall, the present study demonstrates that PCB elimination in round and tubenose goby exhibited broadly similar PCB toxicokinetics as has been measured in other small fish species under limited growth and constant temperature conditions, although species differences in the rate of PCB elimination was evident. This implies that calibrated PCB toxicokinetic parameters, as opposed to generic, allometrically scaled toxicokinetics are more appropriate for use in bioaccumulation models to understand the impact of invasive species such as the round goby on trophic transfer of sediment associated contaminants.

\section{Acknowledgments}

This research was supported by an NSERC Canadian Aquatic Invasive Species Network (CAISN) grant. The authors would like to thank T.Leadley for help with the experimental set-up and animal husbandry. We would also like to thank research technicians J.Robinet and S.n Grigorakis for help with sampling of field animals in the Detroit River.

\section{References}

Chu S, Hong CS (2004) Retention indexes for temperature-programmed gas chromatography of polychlorinated biphenyls. Anal Chem 76:5486-5497.

Connolly JP, Pedersen CJ (1988) A thermodynamic-based evaluation of organic-chemical accumulation in aquatic organisms. Environ Sci Technol 22:99-103

Daley JM, Leadley TA, Drouillard KG (2009) Evidence for bioamplification of nine polychlorinated biphenyl (PCB) congeners in yellow perch (Perca flavascens) eggs during incubation. Chemosphere 75:1500-1505

Drouillard KG, Chan S, O'Rourke S, Haffner GD, Letcher RJ (2007) Elimination of 10 polybrominated diphenyl ether (PBDE) congeners and selected polychlorinated biphenyls (PCBs) from the freshwater mussel, Elliptio complanata. Chemosphere 69:362-370.

Fisk AT, Norstrom RJ, Cymbalisty CD, Muir DCG (1998) Dietary accumulation and depuration of hydrophobic organochlorines: bioaccumulation parameters and their relationship with the octanol/water partition coefficient. Environ Toxicol Chem 17:851-961

Frame GM, Cochran JW, Bewadt SS (1996) Complete PCB congener distributions for 17 Aroclor Mixtures determined by 3 HRGC systems optimized for comprehensive, quantitative, congener-specific analysis. J High Resol Chromatogr 19:657-668.

Gobas FAPC, Zhang X, Wells R (1999) Gastrointestinal magnification - the mechanism of biomagnification and food-chain accumulation of 
organic-chemicals. Environ Sci Technol. 27:2855-2863

Gobas FAPC, MacLean LG (2003) Sediment-water distribution of organic contaminants in aquatic ecosystems: The role of organic carbon mineralization. Environ Sci Technol 37:735-741

Hansen BJ, Paya-Perez AB, Rahman M, Larsen BR (1999) QSARs for Kow and KOC of PCB congeners: A critical examination of data, assumptions and statistical approaches. Chemosphere 39:2209-2228.

Hattula ML, Karlog O (1973) Absorption and elimination of polychlorinated biphenyls (PCB) in goldfish. Acta Pharmacol Toxicol 32:237-245

Hecky RE, Smith REH, Barton DR, Guildford SJ, Taylor WD, Charlton MN, Howell $T$ (2004) The nearshore phosphorus shunt: A consequence of ecosystem engineering by dreissenids in the Laurentian Great Lakes. Can J Fish Aquat Sci 61:1285-1293

Johnson TB, Bunnell DB, Knight, CT (2005) A potential new energy pathway in central Lake Erie: the round goby connection. J Great Lakes Res 31(S2): 238-251

Kocovsky PM, Tallman JA, Jude DJ, Murphy DM, Brown JE, Stepien CA (2011) Expansion of tubenose gobies (Proterorhinus semilunaris) into Western Lake Erie and potential effects on native species. Biol Invasions 13:2775-2784.

Lazar R, Edwards RC, Metcalfe CD, Metcalfe T, Gobas FAPC, Haffner GD (1992) A simple, novel method for the quantitative analysis of coplanar (non-ortho substituted) polychlorinated biphenyls in environmental samples. Chemosphere 25: 493-504

Li J, Drouillard KG, Branfireun B, Haffner GD (2015) Comparison of the toxicokinetics and bioaccumulation potential of mercury and polychlorinated biphenyls in goldfish (Carassius auratus). Environ Sci Technol 49: 11019-11027

Morrison HA, Whittle DM, Haffner GD (2000) The relative importance of species invasions and sediment disturbance in regulating chemical dynamics in western Lake Erie. Ecol Modelling 125: 279-294

Ng CA, Berg MB, Jude DJ, Janssen J, Charlebois PM, Amaral LAN, Gray KA (2008) Chemical amplification in an invaded food web: Seasonality and ontogeny in a high-biomass, low-diversity ecosystem. Enviro Toxicol Chem 27:2186-2195

Niimi AJ, Oliver BG (1983) Biological half-lives of polychlorinated biphenyl (PCB) congeners in whole fish and muscle of rainbow trout (Salmo gairdneri). Can J Fish Aquat Sci 40:1388-1394

O'Neil JA, Johnson TB, Drouillard KG (2013) Validation of rapid assimilation of PCBs. Bull Environ Contam Toxicol 91:135-140

Paterson G, Drouillard KG, Haffner G (2007) PCB elimination by yellow perch (Perca flavescens) during an annual temperature cycle. Environ Sci Technol 41: 824-829.

Vanderploeg HA, TF Naleopa, DJ Jude, EL Mills, KT Holeck, JR Liebig, IA Grigorovich, H Ojaveer (2002) Dispersal and emerging ecological impacts of Ponto-Caspian species in the Laurentian Great Lakes. Can J Fish Aquat Sci 59:1209-1228. 

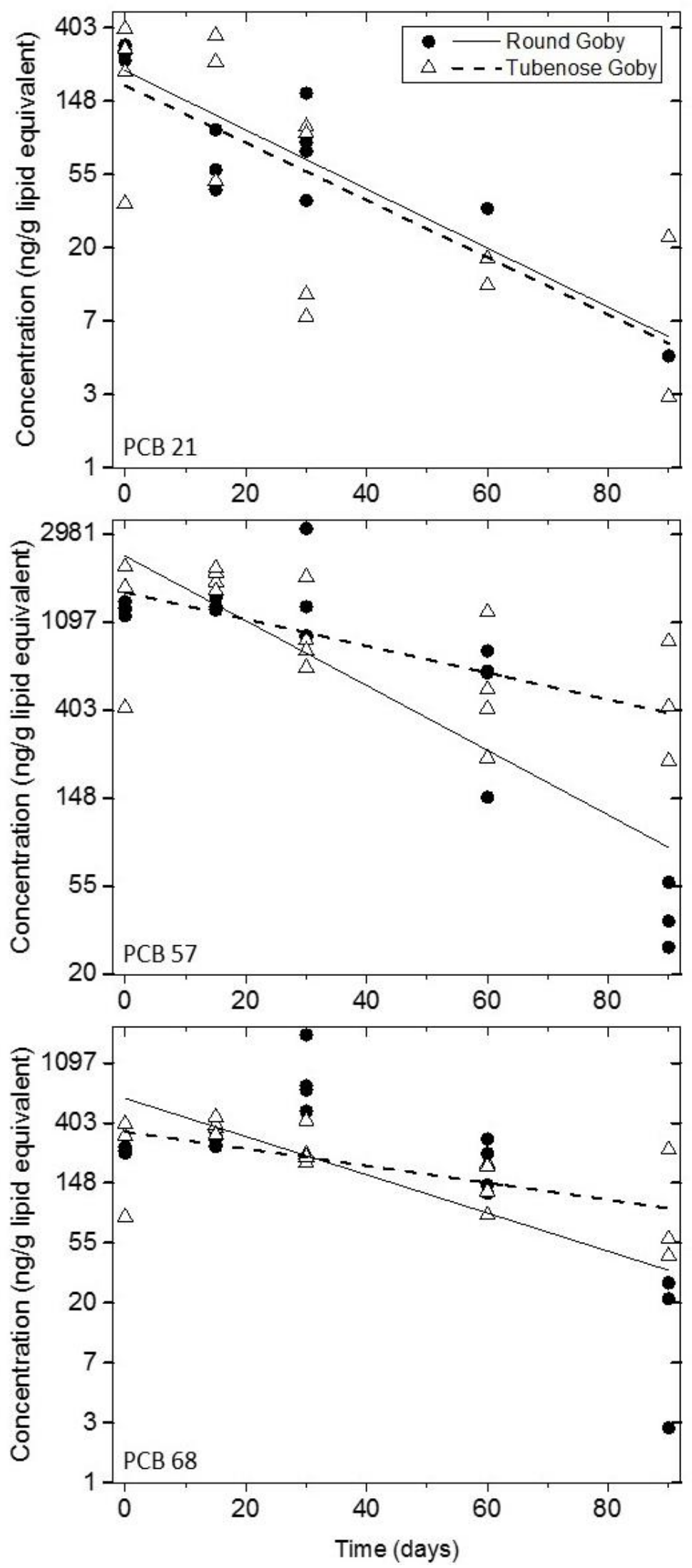

Figure 1. Elimination of selected PCBs with time

364 for round goby and tubenose goby 


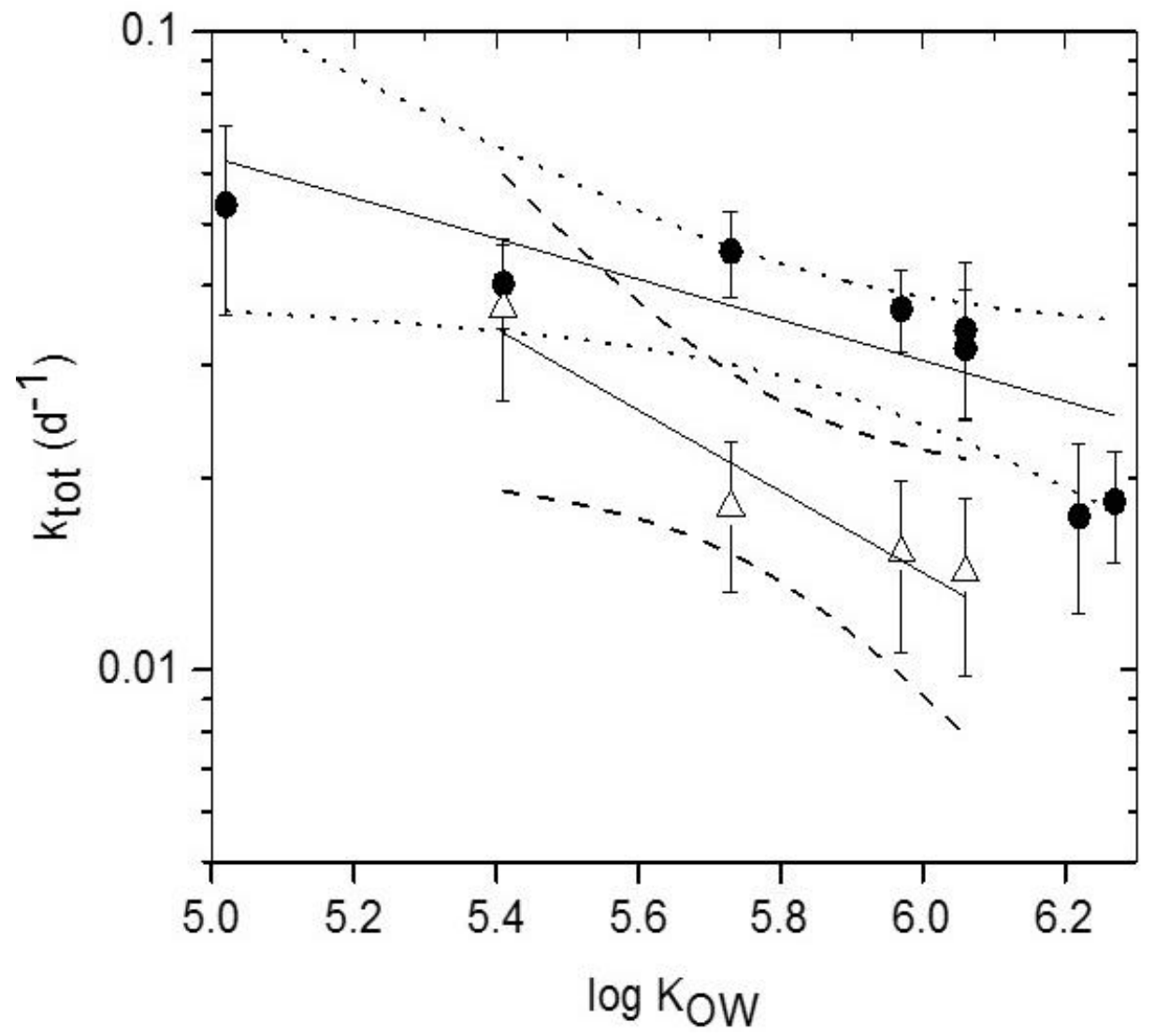

Figure 2. Elimination rate coefficients of PCBs in

368 round goby $(\bullet)$ and tubenose goby $(\Delta)$. Error bars are standard error of the slope estimate. Solid lines are linear regression fits to the data. Dotted line is the 95\% confidence interval around round goby fit. Dashed goby fit 